\title{
The Effect of the Relationship between Organizational Excellence and Quality of Work-Life on Organizational Commitment: An Applied Study on the Health Services Sector in Taif City
}

\author{
Mohammed Farag Alaqla \\ Dept. of Management, Taif University \\ P. O. Box 11099, Taif 21944, Saudi Arabia \\ E-mail: m.alaqla@tu.edu.sa
}

Received: April 19, 2020 Accepted: May 19, 2020 Online published: May 25, 2020

doi:10.5296/ijhrs.v10i2.16860ＵRL: https://doi.org/10.5296/ijhrs.v10i2.16860

\begin{abstract}
Over the last era of the twentieth century, rapidly drastic changes in the economic environment have occurred. These changes have led to increasing the intensity of global competition. Therefore, the organizations' success and survival are nowadays dependent on their rapid response to adapt to the ongoing changes. This paper mainly aims to examine the relationship between organizational excellence, quality of work-life, and organizational commitment. It also aims to identify differences among the respondents' perceptions about their awareness of organizational excellence, the quality of work-life, and organizational commitment. To this end, the descriptive and analytical approaches were adopted to achieve the objectives of the study through collecting, describing, and analyzing data to examine the hypothesized relationships between the variables of the study. Data from published research, journals, and periodicals, in addition to data based on a field study, were used for analysis. The respondents of the study included employees in the health sector (government hospitals) in Taif City, namely doctors, nursing staff, and managers of medical departments. The results showed that there is a statistically significant effect of organizational excellence on both the quality of work-life and organizational commitment. It was found that there is no significant difference among the respondents' perceptions about their awareness of organizational excellence, the quality of work-life, and organizational commitment according to their profession. Accordingly, it is recommended to emphasize the requirements of organizational excellence requirements regarding the leadership of the Saudi health institutions and review strategies, which are developed based on the standards of excellence.
\end{abstract}




\section{MlMacrothink}

International Journal of Human Resource Studies

ISSN 2162-3058

2020, Vol. 10, No. 2

Keywords: organizational excellence, organizational commitment, work-life quality, leadership, human resources

\section{Introduction}

Today's era is characterized by hi-tech, which is regarded as a tool for its progress. Over the last era of the twentieth century, rapidly drastic changes in the economic environment have occurred. Among these changes were the wide openness of trade and the disappearance of restrictions between countries and nations, privatization, globalization, integration, and a combination of technologies of computer, communications, and electronics to form the most challenging technology of our time, namely Information Technology (IT). Also, these changes have led to increasing the intensity of global competition; the organizations' success and survival are nowadays dependent on their rapid response to adapt to the ongoing changes. This certainly requires the necessity of a continuous shift towards increasing the level of the organization's mechanisms and using advanced information technology to remain competitive and to survive. Therefore, competitiveness has become a reality that determines the success or failure of organizations. Those, which possess the keys to excellence and the tools of the industry of excellence can create a better competitive reality and can shift from the reality of comparative advantage to competitive advantage to achieve excellence and success, which makes organizations stronger and better in performance, productivity, and general well-being to maintain their competitive position to encounter challenges and rivalry among domestic and potential competitors. This, in turn, made organizations realize the importance of 'management of excellence' as an activity and planned organizational efforts, which aim at achieving the permanent competitive advantages of the organization through reaching out for products, markets, technology operations, and new methods. However, modern organizations need another complementary process, namely 'management of excellence'. Accordingly, organizational excellence involves enhancements of quality, including a set of values, incentives, as well as activities that lead to achieving distinctive accomplishments; it is a driving force and encouragement for the creation of development to achieve the desired quality, the growth of individuals and teams, and the growth of the organization (Meško Štok et al., 2010). Tammaru and Kiitam (2010) believed that organizational excellence originates from the organization's commitment to a specific vision and focus on innovation and customer service, the development of the work environment, creating high-performance standards, and directing the attention toward an efficiency criterion when recruiting leaders and managers.

Therefore, organizational excellence contributes to increasing the likelihood of the organizations' success in the long run by increasing their ability to create the desired effect to enhance the satisfaction of stakeholders. In the same vein, Klefsjö et al. (2008) added that organizational excellence can be achieved partly by combining quality excellence (quality of the goods or services) and excellence in managing all other aspects of the business. Accordingly, when the organization strives to achieve the standards of excellence, this contributes to improving the various aspects that affect employees' career and behaviour (Lau \& May, 1998). 


\section{Problem Statement}

Organizations, which hold on to a rigid management approach for a long time, will find it difficult to find a prominent competitive place for themselves in the market. Therefore, organizations respond to various drivers that support excellence. In general, the most significant supporting drivers can be identified as follows: 1) rapid change rates, 2) unlimited competition, 3) maintaining position and status, and 4) information technology. To identify the study problem, the researcher conducted a pilot study, and the results revealed some important aspects of the phenomenon in question. There is a Variation among employees about job satisfaction, which results from wage systems, incentives, and promotions. Also, a Variation in the perceptions among employees regarding the management's appreciation of the importance of their work. The employees' perceptions about the importance of continuing in the health institution and the employees' values of organizational commitment were also varied. Therefore, this study aims to examine whether there is a significant difference among the respondents' perceptions about their awareness of organizational excellence, the quality of work-life, and organizational commitment, and investigate the impact of organizational excellence on organizational commitment when mediating the role of the quality of work-life.

\section{Literature Review}

\subsection{Organizational Excellence}

The concept of "excellence" expresses the need for a comprehensive approach that combines the elements and components of building organizations on superior foundations, which have high capabilities to encounter changes and external conditions that surround them. It also achieves complete coherence and consistency between its components and invests its core competencies and superiority in the market to provide the benefits to the stockholders of the organization, including owners, employees, customers, and society. Excellence means innovation, which means doing different things from others, competitively or non-competitively by creating a new market segment through innovation. Excellence also means creating a competitive advantage by being the best in one or more aspects (cost, quality, flexibility, and innovation). Excellence involves giving up the old and investing in the new faster than competitors. The concept of "excellence management" or "management of excellence" is based on a clear intellectual framework that adopts complementarity and interdependence and adheres to the logic of systematic thinking, which the organization sees as an integrated system whose elements interact, its mechanisms are intertwined, and its outputs are the result of their combined capabilities. Excellence management is, therefore, the ability to manage the organization's components in a coordinated manner to achieve high levels of effectiveness, and outputs meet the stakeholders' desires, benefits, and expectations.

Li, Zhao, and Lee (2001) studied how to achieve organizational excellence and develop a theoretical model for the concepts of total quality (meeting customer needs, building self-confidence, respect and mutual trust, employee participation, continuous improvement, optimal use of resources) to achieve the best results. Kanji (2002) identified organizational excellence, and the study emphasized the importance of developing and implementing a performance measurement system to achieve success. In a previous study conducted in 
Australia, Khoo and Tan (2002) proposed a model for organizational excellence, in which leadership, strategies, plans, information, employees, consumer value, operations management, and business results are represented. The results of the study emphasized the importance of focusing on all elements of the model to achieve organizational excellence. In another study by Irani, Beskese, and Love (2004), the researchers pointed out that quality and customers, continuous improvement, and innovation can help build a strong culture in the organization in a manner that leads to improving competitiveness, improving job performance, and achieving organizational excellence. In the same vein, Kanji (2005) examined the relationship between performance measurement and organizational excellence. The model focused on two groups. The first group included leadership, the satisfaction of customers, employee management, continuous improvement, and management with goals and facts. The second group involves the values of the organization, organizational learning processes, and meeting the needs of stakeholders.

In a study by Sharma and Kodali (2008), developed a model for measuring organizational excellence which consists of manufacturing strategy, leadership, knowledge management, micro-manufacturing, change management, flexible operations, customer relationship management, creative product planning, total quality management, global maintenance systems, and environmental manufacturing. Jayamaha, Mann, and Grigg (2008) examined the suitability of three models of organizational excellence used in Australia and Asia. They also examined the relationship between some factors of organizational excellence (such as leadership \& performance) and business results (such as the results of stakeholders). The study concluded that there are specific factors in the three organizational excellence models that are more influential than others in predicting the results for a specific group of stakeholders. Their results were in line with the results by (Saunders et al., 2008). In the health services sector, Tagnesi, et al. (2009) emphasized opportunities and initiatives, which can be taken by the chief nursing officer and key members of the health care team to meet the challenges of the rapid growth of the health care system to achieve organizational excellence. The results showed that there are challenges to achieving organizational excellence, represented in the nature of the organizational structure, organizational culture despite the availability of knowledge and the continuous improvements of the organizational structure. From another perspective, Tutuncu and Kucukusta (2010) found a significant relationship between organizational excellence and job satisfaction. Also, the results showed that leadership, partners, resources, operations, policy, strategy, individual development, participation in decision-making supervision, results, promotion, and co-workers are the determinants of job satisfaction. Meško Štok et al. (2010) studied the effect of organizational culture on organizational excellence and concluded that there is a positive impact between the elements of culture on organizational excellence, especially the elements represented in the structure of communications, personal relationships, motivation, and enthusiasm. Furthermore, Majstorovic (2003) proposed a new model for organizational excellence (BEM) to improve and evaluate the quality of industrial systems. The implementation of the organizational excellence model contributes to the development of the organizational excellence of the manufacturing system, which depends on improving the quality of products. 


\subsection{Quality of Work-Life}

The concept of a work environment includes the physical environment, reward systems, work teams, opportunities for growth, relationship development, and job security and stability. Therefore, Hassanein (1997) believes that quality of work-life involves a set of integrated, planned and continuous operations to improve various aspects that affect work and personal lives of employees in a manner that achieves the strategic goals of the organization. In this context, Mustafa (1999) investigated methods for measuring the quality of work-life, and the study emphasized the importance of having many factors to achieve the quality of work-life, including participation in decision-making, work teams, job security, providing information, equality in returns, wages, and supervisory behaviour.

In the same vein, Konrad and Mangel (2000) examined the effect of quality of work-life programs on productivity, and the study concluded that there are positive and strong correlation and impact between work-life quality programs and productivity. The study also found a relationship between the application of quality of work-life programs and reducing turnover rates, delay and absence rates. Regarding the performance of hospitals, Labiris, et al. (2002) assessed the effect of quality of work-life on hospital performance and concluded that employees' performance depends on rehabilitation, the availability of financial and moral assistance, the provision of a safe and healthy work environment, fair and adequate payment, the satisfaction of social needs, and the degree of participation in decision-making. Jalal (2005) examined the influence of managers' strengths on the quality of work-life and the impact of the quality of work-life on the performance of particular units. The study identified the nature of direct and indirect effects of the strengths of managers on the performance of these units. The study found that there is an effect of the power of experience and position on the quality of work life. However, no significant effect of official power on the quality of work-life was revealed. The study showed that there is a significant effect of the quality of work-life on the performance of particular units. On the other hand, Kriel (2006) examined the relationship between ethics, job ethics, and justice with work-life quality. A strong positive relationship was identified between ethics, job ethics, and justice and the quality of work life. Therefore, the study emphasized that job ethics and personal ethics are interrelated to achieve higher work-life quality. Rethinam and Ismail (2008) identified the determinants of work quality from the technology and information professionals' perspective. The results emphasized the importance of these factors, including job security and job satisfaction, providing high levels of health and welfare services and developing efficiency, striking a balance between working times and personal life, and the transition of the contemporary workforce into a knowledge-based workforce.

\subsection{Organizational Commitment}

Organizational commitment is a key factor in the success of the organization, and employees, who are committed, look after their organization and put in sincere efforts to ensure its success, productivity, and well-being. Organizational commitment is a multidimensional concept, which is often interpreted in different ways (Mathews \& Shepherd, 2002). Nowadays, the most common method of studying this concept is through the attitudes and 
perceptions of individuals towards the organization. Mathews and Shepherd (2002) indicated that "employees, who adhere to a strong belief in the goals and values of the organization, demonstrate their desire to make a major effort in the organization, and have a strong desire to maintain their membership of the organization". Zangaro (2001) defined organizational commitment as "an act of making a promise to fulfil the obligation of a person or thing at a later time". Also, he explained that "a person, who is committed to the organization, should be dedicated to his/her work, having a strong belief in the goals and values of the organization". Organizational commitment is one of the fundamental aspects of stabilizing the relationship between individuals and the organization (Riketta, 2002). Organizational commitment exerts an impact on many individual behaviours in the organization. It exerts an effect on the efficiency and effectiveness of organizations as many organizations can avoid economic, social, and psychological consequences at the individual and group levels It involves harmony between the goals of the individual and the goals of the organization (Meyer \& Allen, 1991). Wong, et al. (2001) studied the relationship between organizational commitment, job satisfaction, and technical employees' intentions of leaving work and found a direct impact of organizational commitment on job satisfaction.

In another study, Meyer and Herscovitch (2001) examined the relationship between three forms of commitment to the organization including affective, continuance, and moral commitment with the variables that may cause these forms of commitment. The study concluded that the three forms of commitment are interrelated. However, there are no variables that can cause moral commitment. A study by Najm (2003) examined the relationship between human resource (independent variable), job satisfaction (mediator), and organizational commitment (dependent variable). A positive effect of promotion and wages on organizational commitment was revealed. Moreover, there was no evidence of a significant direct effect of the incentives and employee training variables on the organizational commitment, when mediating job satisfaction. However, wages, incentives, training, and promotion exert an effect on organizational commitment. Hassanein (1997) examined the relationship between employee awareness of organizational justice, organizational commitment in the city councils of the Dakahlia governorate. The results showed no significant difference between categories of administrators and executives regarding the awareness of organizational justice; a relationship is found between the dimensions of organizational justice in organizations, as well as a difference between the category of administrators and the category of executives regarding the level of organizational commitment. Chughtai and Zafar (2006) examined the relationship between job satisfaction, job commitment, and labour turnover. A direct relationship was found between job satisfaction, organizational commitment, and labour turnover; higher levels of job satisfaction and organizational commitment result in fewer turnover rates. A positive significant effect of job satisfaction on organizational commitment was also revealed. In the Saudi context, Nafe'a (2009) studied work values and their impact on the organizational commitment of different categories of employees in King Abdul-Aziz Hospital in Saudi Arabia. The study concluded that there is no significant difference between different categories of employees about their evaluation perceptions towards work values (internal, external), on the one hand, and organizational commitment on the other hand. A relationship 
was revealed between the dimensions of internal work values (a sense of pride in belonging to an organization, integration, work preference, economic value of work, the social value of work) and the level of organizational commitment. For employees, the results of the study showed a statistical relationship between the dimensions of external work values (the need for progress, the motivation to accomplish, and employee engagement) and the level of employees' organizational commitment. Panaccio and Vandenberghe (2009) examined the role of perceived organizational support and the four dimensions of organizational commitment (affective, moral, perceived commitment of sacrificing to leave the organization, and realizing that there are no alternatives) to maintain the psychological well-being of workers. It was found that affective commitment positively mediates the relationship between the perception of organizational support and well-being. A negative relationship was found between perceived organizational support, awareness of the limited alternatives that have a negative relationship with well-being. Regarding moral commitment, the perception of leaving work has not been proven to relate to well-being.

Liu and Cohen (2010) examined the relationship between individual values, organizational and professional commitment, and citizenship organizational behaviours. The results showed that continuance commitment plays a key role, as a dependent variable (influenced by values) or as an independent variable (influencing organizational citizenship behaviours). Also, the results showed that there is a positive effect of continuance commitment on organizational citizenship behaviours, a strong relationship between values, continuance commitment, and a strong negative relationship between personal perception and all forms of commitment. In the nursing sector, Ahmad and Oranye (2010) studied the relationship between employee empowerment, job satisfaction, and organizational commitment of nurses working in Malaysia and England. A positive impact was found between employee empowerment and affective organizational commitment among nurses in Malaysia. When using job satisfaction as a mediator, employee empowerment exerts a more positive impact on the organizational commitment of nurses in England.

\section{Methodology}

This study mainly aims to 1) identify differences among the respondents' perceptions about their awareness of organizational excellence, the quality of work-life, and organizational commitment and 2) identify the effect of organizational excellence on organizational commitment through the mediating role of the quality of work-life on affective commitment, moral commitment, and continuance commitment. Based on the objectives of the study, the following questions are addressed:

1) Is there a significant difference among the respondents' perceptions about their awareness of organizational excellence, the quality of work-life, and organizational commitment?

2) Is there a statistically significant effect of organizational excellence on organizational commitment when mediating the role of the quality of work-life? 


\subsection{Research Design}

A case study design is implemented in this research, which provides detailed insight into the factors that help the researcher address real-life situations related to the objectives of the study. The case study involves the Saudi health services sector, particularly the government hospitals in Taif City, Saudi Arabia.

\subsection{Hypotheses of the Study}

Based on reviewing the previous studies, the following hypotheses are formulated:

H.1 There is no significant difference among the respondents' perceptions about their awareness of organizational excellence, the quality of work-life, and organizational commitment.

H.2 There is no statistically significant effect of organizational excellence on organizational commitment when using the quality of work-life as a mediator. This hypothesis can be divided into sub-hypotheses as follows:

a) There is no statistically significant effect of organizational excellence on work-life quality.

b) There is no statistically significant effect of organizational excellence and work-life quality on organizational commitment.

c) There is no statistically significant effect of organizational excellence and work-life quality on affective commitment.

d) There is no statistically significant effect of organizational excellence and work-life quality on moral commitment.

e) There is no statistically significant effect of organizational excellence and work-life quality on continuance commitment.

\subsection{Data Collection}

The methodology of this study mainly involves the quantitative approach, which relies on primary data that can be collected by the researcher through a survey or interviews. Secondary data were also used in this study, i.e., previous data and studies in the field of studying the factors that influence employees' turnover, which is addressed in the literature review section.

\subsection{Target Population}

The study sample consists of employees in the health sector (government hospitals) in Taif City, including doctors, nursing staff, and managers of medical departments. The total number of doctors is 453 , the total number of the nursing staff is 330 , and the total number of employees is 81 (employee management records) In the selected hospitals in Taif City, Saudi Arabia. A total number of 400 respondents were chosen with an increase of 16 respondents based on the maximum sample size (Ba-zara'a, 1995). Table 1 illustrates the distribution of the sample size and the frequency and percentages of sampling size according to the respondents' profession. 


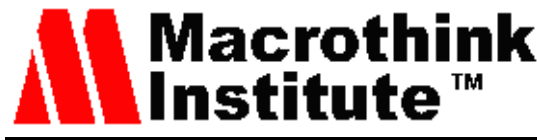

The data were collected via a survey questionnaire designed for this purpose. The researcher collected and reviewed the questionnaires to ensure that the answers are complete and to exclude the incomplete questionnaires. A total of 342 questionnaires were returned and 27 incomplete questionnaires were excluded. Therefore, the sample size included 315 questionnaires for statistical analysis with a response rate of $79 \%$.

Table 1. Distribution of sample size according to the profession of respondents

\begin{tabular}{lccccc}
\hline Profession & Population Size & $\boldsymbol{\%}$ & Sample Size & Returned Surveys & $\boldsymbol{\%}$ \\
\hline Doctor & 453 & 52.4 & 210 & 165 & 52.4 \\
Nurse & 330 & 38.2 & 152 & 120 & 38.1 \\
Manager & 81 & 9.4 & 38 & 30 & 9.5 \\
\hline Total & 864 & 100 & 400 & 315 & 100 \\
\hline
\end{tabular}

\subsection{Measurement of Variables}

The variables of this study include organizational excellence, the quality of work-life, and organizational commitment. The measurement of organizational excellence was determined based on several studies that investigated the ability to achieve organizational excellence (Bou-Llusar et al., 2009; Jochen, Loizos, \& Nitin, 2008; Lok \& Crawford, 2004; Muchiri et al., 2011). The statistically tested tool, which has proven its validity and reliability to measure organizational excellence, was used. The measurement tool includes five constructs: leadership, strategy, human resources, companies and resources, and operations. The measurement of the quality of work-life was determined based on several studies, in addition to a survey questionnaire prepared by the National Institute for Occupational Safety and Health (Niosh, 2002) entitled 'Quality of work-life' to measure and evaluate the quality of work-life (El-Maghraby, 2004). The measurement tool includes six constructs, including work conditions, job characteristics, wages, rewards, group work, the main method of supervision, and participation in decisions. The measurement of organizational commitment was determined based on several studies (Allen \& Meyer, 1990; Steyrer et al., 2008; Wasti, 2005). The measurement tool includes the following variables: affective commitment, moral commitment, and continuance commitment.

\subsection{Reliability and Validity of the Questionnaire}

The measurement of the scale of reliability (Cronbach's Alpha) was calculated for the questions of the survey questionnaire. The values of the reliability coefficient are acceptable for all the survey questions. The questionnaire includes three main constructs, which consist of more than one component. The obtained values were 0.79 the organizational excellence and 0.86 for the quality of work-life. Also, the values of the validity coefficient ranged were 0.89 for the organizational excellence and 0.93 , for the quality of work-life. Therefore, the obtained values are parameters of good significance to achieve the objectives of the study and generalize the results to the entire population of the society.

\section{Data Analysis and Discussion}

Regarding the first hypothesis testing, descriptive statistics of the study variables 
(organizational excellence, quality of work-life, and organizational commitment) are illustrated in Table 4 based on the respondents' categories according to their profession (doctors, nursing staff, and managers of medical departments). Regarding 'group work' component as one of the dimensions of quality of work-life, the doctors' perceptions recorded an average of (4.32) with a standard deviation of (0.070), whereas an average of (41.4) and a standard deviation of (0.09) was recorded for the nursing staff. The medical department managers' perceptions of the two components of 'work conditions' and 'job characteristics' as dimensions of the quality of work-life were recorded with an average of $(4,92)$. The decrease in the standard deviation showed a decrease in the difference between the perceptions of each of the study categories.

Table 2. Descriptive statistics of the study variables and Kruskal-Wallis test results

\begin{tabular}{|c|c|c|c|c|c|c|c|c|}
\hline $\begin{array}{c}\text { Component of the Study } \\
\text { Variables }\end{array}$ & \multicolumn{2}{|c|}{ Doctors } & \multicolumn{2}{|c|}{ Nursing Staff } & \multicolumn{2}{c|}{$\begin{array}{c}\text { Managers of } \\
\text { Departments }\end{array}$} & $\begin{array}{c}\text { Chi- } \\
\text { Square }\end{array}$ & P-Value \\
\cline { 2 - 9 } & Mean & SD & Mean & SD & Mean & SD & & \\
\hline Organizational Excellence & 4.01 & 0.48 & 3.93 & 0.54 & 4.64 & 0.43 & 28.573 & 0.000 \\
\hline Leadership & 4.19 & 0.6 & 4.15 & 0.70 & 4.75 & 0.44 & 18.715 & 0.000 \\
\hline Strategy & 3.99 & 0.66 & 4.00 & 0.68 & 4.63 & 0.58 & 18.729 & 0.000 \\
\hline Human Resources & 4.07 & 0.61 & 3.90 & 0.68 & 4.67 & 0.48 & 24.686 & 0.000 \\
\hline Firms \& Resources & 3.77 & 0.59 & 3.70 & 0.64 & 4.54 & 0.59 & 29.101 & 0.000 \\
\hline Operations & 4.05 & 0.74 & 3.92 & 0.80 & 4.63 & 0.58 & 15.368 & 0.000 \\
\hline Quality of Work-Life & 4.11 & 0.54 & 4.10 & 0.54 & 4.67 & 0.30 & 24.901 & 0.000 \\
\hline Work Conditions & 4.25 & 0.73 & 4.08 & 0.80 & 4.92 & 0.41 & 23.846 & 0.000 \\
\hline Job Characteristics & 4.27 & 0.72 & 4.13 & 0.81 & 4.92 & 0.28 & 21.148 & 0.000 \\
\hline Wages, Rewards & 3.94 & 0.89 & 3.85 & 0.89 & 4.42 & 0.88 & 6.988 & 0.030 \\
\hline Group Work & 4.32 & 0.7 & 4.41 & 0.69 & 4.79 & 0.41 & 10.419 & 0.005 \\
\hline Main method of Supervision & 3.91 & 0.65 & 3.89 & 0.64 & 4.29 & 0.55 & 7.892 & 0.019 \\
\hline Participation in Decisions & 3.89 & 0.72 & 4.21 & 0.69 & 4.67 & 0.48 & 20.610 & 0.000 \\
\hline Organizational Commitment & 3.93 & 0.57 & 4.13 & 0.47 & 4.50 & 0.35 & 23.993 & 0.000 \\
\hline Affective Commitment & 3.89 & 0.68 & 4.10 & 0.57 & 4.71 & 0.46 & 31.084 & 0.000 \\
\hline Moral Commitment & 4.07 & 0.76 & 4.26 & 0.63 & 4.63 & 0.58 & 13.122 & 0.001 \\
\hline Continuance Commitment & 3.83 & 0.61 & 4.02 & 0.56 & 4.17 & 0.70 & 8.202 & 0.017 \\
\hline
\end{tabular}

To identify the significance of the difference between the respondents' perceptions, the Kruskal-Wallis test was used. It is one of the non-practical tests, which is used to test the difference between more than two averages, that is, an alternative test for ANOVA variance analysis, to test that there is no significant difference between the perceptions of the respondents on the study variables (organizational excellence, quality of work-life, and organizational commitment) according to their profession (doctors, nursing staff, and managers of medical departments). Based on Table 2, all the components of the study recorded 5\% significance, and the values of P-Value were less than the level of significance. The results, therefore, showed no significant difference among the respondents' perceptions 
about the variables (organizational excellence, quality of work-life, and organizational commitment) according to their profession. Therefore, based on the results, the first hypothesis was supported. This result does not go in line with the results of (Katsikea et al., 2011; Weng et al., 2010); they found a relationship between profession, job feedback, job satisfaction, and organizational commitment.

Table 3. The estimates of the partial regression model for the dependent variable regression

\begin{tabular}{|c|c|c|c|c|c|c|c|}
\hline \multirow[b]{2}{*}{$\mathbf{H} 2$} & \multirow{2}{*}{$\begin{array}{l}\text { Independent } \\
\text { Variables }\end{array}$} & \multicolumn{5}{|c|}{ Estimates } & \multirow[b]{2}{*}{ Rank } \\
\hline & & \begin{tabular}{|l|} 
Correlation \\
Coefficient \\
\end{tabular} & \begin{tabular}{|c|}
$\begin{array}{c}\text { Partial Regression } \\
\text { Coefficients }\end{array}$ \\
\end{tabular} & $\begin{array}{c}\text { Standard Partial } \\
\text { Regression Coefficient }\end{array}$ & $\mathbf{T}$ & Sig. & \\
\hline \multirow{7}{*}{ H2a } & (Constant) & - & 1.042 & - & 6.313 & 0.000 & - \\
\hline & Leadership & 0.435 & 0.005 & 0.006 & 0.111 & 0.911 & - \\
\hline & Strategy & 0.650 & 0.214 & 0.268 & 4.207 & 0.000 & 2 \\
\hline & Human Resources & 0.598 & 0.099 & 0.118 & 2.187 & 0.030 & 4 \\
\hline & Companies \& Resources & 0.682 & 0.159 & 0.189 & 3.423 & 0.001 & 3 \\
\hline & Operations & 0.737 & 0.300 & 0.419 & 7.795 & 0.000 & 1 \\
\hline & F value $=99.12$ & \multicolumn{2}{|c|}{ Significance $=0.000$} & \multicolumn{4}{|c|}{ Coefficient of determination $=\mathbf{0 . 6 8 5}$} \\
\hline \multirow{8}{*}{$\mathbf{H} 2 \mathbf{b}$} & (Constant) & - & 0.691 & - & 3.305 & 0.001 & - \\
\hline & Leadership & 0.566 & 0.322 & 0.314 & 6.418 & 0.000 & 2 \\
\hline & Strategy & 0.540 & 0.045 & 0.055 & 0.728 & 0.467 & - \\
\hline & Human Resources & 0.356 & 0.207 & 0.242 & 3.867 & 0.000 & 3 \\
\hline & Companies \& Resources & 0.574 & 0.177 & 0.207 & 3.185 & 0.002 & 4 \\
\hline & Operations & 0.551 & 0.048 & 0.067 & 0.958 & 0.339 & - \\
\hline & Work-Life Quality & 0.662 & 0.326 & 0.320 & 4.511 & 0.000 & 1 \\
\hline & $\mathrm{F}$ value $=\mathbf{1 1 2 . 8 5 3}$ & \multicolumn{2}{|c|}{ Significance $=0.000$} & \multicolumn{4}{|c|}{ Coefficient of determination $=\mathbf{0 . 7 7 2}$} \\
\hline \multirow{8}{*}{ H2c } & (Constant) & - & 0.107 & - & 0.436 & 0.633 & - \\
\hline & Leadership & 0.423 & 0.138 & 0.129 & 2.341 & 0.020 & 5 \\
\hline & Strategy & 0.524 & 0.080 & 0.081 & 1.110 & 0.268 & - \\
\hline & Human Resources & 0.404 & 0.172 & 0.165 & 3.732 & 0.007 & 4 \\
\hline & Companies \& Resources & 0.684 & 0.322 & 0.209 & 3.935 & 0.000 & 2 \\
\hline & Operations & 0.668 & 0.171 & 0.193 & 2.874 & 0.004 & 3 \\
\hline & Work-Life Quality & 0.709 & 0.429 & 0.345 & 4.712 & 0.000 & 1 \\
\hline & F value $=107.622$ & \multicolumn{2}{|c|}{ Significance $=0.000$} & \multicolumn{4}{|c|}{ Coefficient of determination $=0.692$} \\
\hline \multirow{8}{*}{ H2d } & (Constant) & - & 0.281 & - & 2.903 & 0.003 & - \\
\hline & Leadership & 0.587 & 0.442 & 0.330 & 4.539 & 0.000 & 2 \\
\hline & Strategy & 0.469 & 0.015 & 0.015 & 0.169 & 0.866 & - \\
\hline & Human Resources & 0.276 & 0.264 & 0.235 & 3.313 & 0.001 & 3 \\
\hline & Firms \& Resources & 0.397 & 0.148 & 0.132 & 0.793 & 0.074 & 5 \\
\hline & Operations & 0.332 & 0.140 & 0.147 & 1.867 & 0.063 & 4 \\
\hline & Work-Life Quality & 0.519 & 0.508 & 0.365 & 4.785 & 0.000 & 1 \\
\hline & $F$ value $=134.703$ & \multicolumn{2}{|c|}{ Significance $=0.000$} & \multicolumn{4}{|c|}{ Coefficient of determination $=0.802$} \\
\hline \multirow{8}{*}{ H2e } & (Constant) & - & 0.315 & - & 5.341 & 0.000 & - \\
\hline & Leadership & 0.470 & 0.076 & 0.274 & 3.505 & 0.001 & 2 \\
\hline & Strategy & 0.428 & 0.093 & 0.043 & 0.417 & 0.677 & - \\
\hline & Human Resources & 0.490 & 0.281 & 0.195 & 2.293 & 0.023 & 3 \\
\hline & Firms \& Resources & 0.229 & 0.084 & 0.064 & 0.719 & 0.473 & - \\
\hline & Operations & 0.460 & 0.216 & 0.182 & 1.905 & 0.043 & 4 \\
\hline & Work-Life Quality & 0.693 & 0.417 & 0.315 & 4.074 & 0.000 & 1 \\
\hline & $F$ value $=101.255$ & \multicolumn{2}{|c|}{ Significance $=0.000$} & \multicolumn{4}{|c|}{ Coefficient of determination $=0.687$} \\
\hline
\end{tabular}


Regarding the second hypothesis of the study, the statistical test was performed for the five sub-hypotheses. Table 3 illustrates the estimates of the partial regression model for the dependent variable regression (the average of the respondents' perceptions about the quality of work-life) on the independent variable (organizational excellence) to test the subhypothesis of this study. For sub-hypothesis (a), the significance of the partial regression model for most of the components of organizational excellence was obtained with a percentage and value of $\mathrm{Sig}=0,000$. The most important components of organizational excellence, which affect the quality of work-life as a dependent variable, can be arranged according to the standard partial regression coefficient as follows: 1) operations, 2) strategy, 3) firms and resources, and 4) human resources. This explained $68.5 \%$ of the changes that occurred in the dependent variable (the average of the respondents' perceptions about the quality of work-life). Accordingly, the regression coefficients are positive in the sense that the relationship is direct between the components of organizational excellence and quality of work-life. The greater the organizational excellence is, the greater the employees' sense of the quality of their work-life will be. Therefore, the first sub-hypothesis was not supported.

For sub-hypothesis (b), the significance of the regression model is estimated by the value of $\mathrm{F}$ $(\mathrm{F}=112.583)$ and the value of $(\mathrm{Sig}=0.000)$. The significance of the partial regression coefficients for most of the components of organizational excellence and quality of work-life is recorded by the value of $\mathrm{t}$ and the value of (Sig). Also, the significance of the constant limit is at the level of $5 \%$ significance with its value $(\mathrm{Sig}=0.00)$. The most important components of organizational excellence and quality of work-life, which affect organizational commitment as a dependent variable, can be arranged according to the standard partial regression coefficient as follows: 1) quality of work-life, 2) human resources, 3) leadership, and 4) firms and resources. This explained $77.2 \%$ of the changes that occurred in the dependent variable (the average of the respondents' perceptions about organizational commitment). The regression coefficients are positive in the sense that the relationship is direct between the components of organizational excellence, the quality of work-life, and organizational commitment. In other words, the greater the organizational excellence and quality of work-life are, the greater the organizational commitment will be. Therefore, the second sub-hypothesis was not supported. This result was in partial agreement with a previous study (Normala, 2010) that showed a positive relationship between the quality of work-life and organizational commitment.

Regarding sub-hypothesis (c), the static limit was not significant at the 5\% level of significance with its value ( $\mathrm{Sig}=0.663)$. Therefore, the most important components of organizational excellence and quality of work-life, which affect emotional commitment a dependent variable, can be arranged according to the standard partial regression coefficient as follows: 1) quality of work-life, 2) operations, 3) firms and resources, 4) human resources, and 5) leadership. This explained $69.2 \%$ of the changes that occurred in the dependent variable (the average of the respondents' perceptions about organizational commitment). It can be observed that the regression coefficients are positive in the sense that the relationship is direct between the components of organizational excellence and the quality of work-life. This means that the greater the organizational excellence and the quality of work-life are, the 
greater the affective commitment will be. Therefore, the third sub-hypothesis was not supported.

Also, Sub-hypothesis (d) was not supported as a result of this test. It is found that the most important components of organizational excellence and the quality of work-life, which affect the moral commitment as a dependent variable, can be arranged according to the standard partial regression coefficients as follows: 1) quality of work-life, 2) leadership, 3) human resources, 4) operations, and 5) firms and resources. This explained $80.2 \%$ of the changes that occurred in the dependent variable (the average of the respondents' perceptions about moral commitment). It can be observed that the regression coefficients are positive and the relationship between the components of organizational excellence, the quality of work-life, and affective commitment, is direct. This means that the greater organizational excellence and the quality of work-life are, the greater the moral commitment will be.

For sub-hypothesis (e), the most important components of organizational excellence and the quality of work-life, which affect the continuance commitment as a dependent variable, can be arranged as follows: 1) quality of work-life, 2) Leadership, 3) human resources, and 4) operations. This explained $68.7 \%$ of the changes that occurred in the dependent variable (the average of the respondents' perceptions about the continuance commitment). It can be observed that the regression coefficients are positive, and the relationship is direct between the components of organizational excellence, the quality of work-life, and continuance commitment. This means that the greater organizational excellence and the quality of work-life are, the greater the continuance commitment will be. Therefore, the fifth sub-hypothesis was not supported.

\section{Conclusion and Recommendations}

The results of this study showed a significant effect of organizational excellence on both the quality of work-life and organizational commitment. Therefore, the management of health institutions in Taif City should emphasize organizational excellence requirements regarding the leadership of these health institutions. This can be achieved through establishing objective criteria for selection and providing programs to develop leaders that enable them to perform in a motivating way for employees and encourage the spirit of cooperation among employees to achieve organizational excellence within these institutions. Besides, encouraging the trend towards change, focusing on the working methods that keep pace with technological developments. They should review the strategies, which are developed based on the standards of excellence with employees' participation. Also, review policies, which are approved by health institutions annually and identify their compliance with the strategic plans of the health institution. Review the vision of the institution, i.e., the message, which is related to each institution and identify its compliance with the health institution's strategic plans.

It is recommended that health management focuses on satisfying customers through realizing their expectations, determining the level of compliance of the health institution with the expectations and evaluating the methods of overcoming the problems of customers. The management of the health institutions in Taif City should emphasize the human factor by establishing objective criteria for selection, appointment, wages, and promotion. They should 
provide the knowledge that helps in adopting methods, thereby allowing employees to easily adapt to technology. The management should also encourage team spirit and inspirational opinions to enhance innovation, moral and physical motivation, and focus on empowering employees in the health services sector in Taif City.

\section{References}

Ahmad, N., \& Oranye, N. O. (2010). Empowerment, job satisfaction and organizational commitment: a comparative analysis of nurses working in Malaysia and England. Journal of Nursing Management, 18(5), 582-591.

Allen, N. J., \& Meyer, J. P. (1990). The measurement and antecedents of affective, continuance and normative commitment to the organization. Journal of Occupational Psychology, 63(1), 1-18.

Ba-zara'a, M. S. (1995). Marketing Research for Planning, Control and Marketing Decision-Making (Fifth Edit). Dar Al-Nahda Al-Arabiya.

Bou-Llusar, J. C., Escrig-Tena, A. B., Roca-Puig, V., \& Beltrán-Martín, I. (2009). An empirical assessment of the EFQM Excellence Model: Evaluation as a TQM framework relative to the MBNQA Model. Journal of Operations Management, 27(1), 1-22.

Chughtai, A. A., \& Zafar, S. (2006). Antecedents and Consequences of Organizational Commitment Among Pakistani University Teacher. Applied H.R.M. Research, 11(1), 39-64.

El-Maghraby, A.-H. A.-F. (2004). The quality of work-life and its impact on the development of job exhaustion: A field study. Journal of Commerce Research, Faculty of Commerce, Zagazig University, 2, 253-305.

Hassanein, J. A.-R. (1997). Quality of Work-Life in Business Sector Companies.

Irani, Z., Beskese, A., \& Love, P. E. D. (2004). Total quality management and corporate culture: constructs of organisational excellence. Technovation, 24(8), 643-650.

Jayamaha, N. P., Mann, R. S., \& Grigg, N. P. (2008). An empirical study of the validity of business excellence models and the relationships between 'enablers' and 'business results.' In K. J. Foley \& P. Hermel (Eds.), The Theories and Practices of Organizational Excellence: NEW PERSPECTIVES (pp. 15-48). SAI Global Limited.

Jochen, W., Loizos, H., \& Nitin, P. (2008). Managing human resources for service excellence and cost-effectiveness at Singapore Airlines. Managing Service Quality: An International Journal, 18(1), 4-19.

Kanji, G. K. (2002). Performance measurement system. Total Quality Management, 13(5), $715-728$.

Kanji, G. K. (2005). Sustainable growth and business excellence. Total Quality Management \& Business Excellence, 16(8-9), 1069-1078.

Katsikea, E., Theodosiou, M., Perdikis, N., \& Kehagias, J. (2011). The effects of 
organizational structure and job characteristics on export sales managers' job satisfaction and organizational commitment. Journal of World Business, 46(2), 221-233.

Khoo, H. H., \& Tan, K. C. (2002). Using the Australian Business Excellence Framework to achieve sustainable business excellence. Corporate Social Responsibility and Environmental Management, 9(4), 196-205.

Klefsjö, B., Bergquist, B., \& Garvare, R. (2008). Quality management and business excellence, customers and stakeholders : do we agree on what we are talking about, and does it matter? The TQM Journal, 20(2), 120-129.

Konrad, A. M., \& Mangel, R. (2000). The impact of work-life programs on firm productivity. Strategic Management Journal, 21(12), 1225-1237.

Kriel, P. (2006). The relationship of morality, ethics and justice to quality of work life. Southern Cross University.

Labiris, G., Petounis, A., Kitsos, G., Aspiotis, M., \& Psillas, K. (2002). Quality Gap, Quality of Work Life and their Impact on the Performance of an Ophthalmologic Department. Journal of Medical Marketing, 3(1), 49-55.

Lau, R. S. M., \& May, B. E. (1998). A win-win paradigm for quality of work-life and business performance. Human Resource Development Quarterly, 9(3), 211-226.

Li, E. Y., Zhao, X., \& Lee, T.-S. (2001). Quality management initiatives in Hong Kong's banking industry: A longitudinal study. Total Quality Management, 12(4), 451-467.

Liu, Y., \& Cohen, A. (2010). Values, commitment, and OCB among Chinese employees. International Journal of Intercultural Relations, 34(5), 493-506.

Lok, P., \& Crawford, J. (2004). The effect of organisational culture and leadership style on job satisfaction and organisational commitment: A cross-national comparison. Journal of Management Development, 23(4), 321-338.

Majstorovic, V. D. (2003). Developed Model for Business Excellence. Manufacturing Systems, 1(3), 1-4.

Mathews, B. P., \& Shepherd, J. L. (2002). Dimensionality of Cook and Wall's (1980) British Organizational Commitment Scale revisited. Journal of Occupational and Organizational Psychology, 75(3), 369-375.

Meško Štok, Z., Markič, M., Bertoncelj, A., \& Meško, M. (2010). Elements of organizational culture leading to business Excellence. Proceedings of Rijeka Faculty of Economics : Journal of Economics and Business, 28(2), 303-318.

Meyer, J. P., \& Allen, N. J. (1991). A three-component conceptualization of organizational commitment. Human Resource Management Review, 1(1), 61-89.

Meyer, J. P., \& Herscovitch, L. (2001). Commitment in the workplace: toward a general model. Human Resource Management Review, 11(3), 299-326. 
Muchiri, M. K., Cooksey, R. W., Di Milia, L. V., \& Walumbwa, F. O. (2011). Gender and managerial level differences in perceptions of effective leadership. Leadership \&amp; Organization Development Journal, 32(5), 462-492.

Mustafa, A. M. (1999). Methods of Measuring Quality of Work-Life. Journal of the Faculty of Commerce for Scientific Research, Faculty of Commerce, Alexandria University, 36(1), 109-189.

Nafe'a, W. A. S. (2009). Work Values and their Impact on Organizational Commitment: An Applied Study in King Abdulaziz Hospital in Taif City, Saudi Arabia”, The Scientific Journal of Trade and Finance, Tanta University: Faculty of Commerce, 1(2), 377-440.

Najm, A.-H. A. (2003). An Analysis of the relationship between several organizations' human resources policies and organizational commitment through mediating job satisfaction. The Egyptian Journal of Business Studies, Mansoura University: Faculty of Commerce, 27(3), 45-82.

Niosh, N. (2002). The changing organization of work and the safety and health of working people.

Normala, D. (2010). Investigating the Relationship between Quality of Work Life and Organizational Commitment amongst Employees in Malaysian Firms. International Journal of Business and Management, 5(10), 75-82.

Panaccio, A., \& Vandenberghe, C. (2009). Perceived organizational support, organizational commitment and psychological well-being: A longitudinal study. Journal of Vocational Behavior, 75(2), 224-236.

Rethinam, G. S., \& Ismail, M. (2008). Constructs of quality of work-life: a perspective of information technology professionals. European Journal of Social Sciences, 7(1), 58-70.

Riketta, M. (2002). Attitudinal organizational commitment and job performance: a meta-analysis. Journal of Organizational Behavior, 23(3), 257-266.

Saunders, M., Mann, R., \& Grigg, N. (2008). Review processes for improving business excellence frameworks. International Journal of Quality \&amp; Reliability Management, 25(9), 928-942.

Sharma, M., \& Kodali, R. (2008). Development of a framework for manufacturing excellence. Measuring Business Excellence, 12(4), 50-66.

Steyrer, J., Schiffinger, M., \& Lang, R. (2008). Organizational commitment-A missing link between leadership behaviour and organizational performance? Scandinavian Journal of Management, 24(4), 364-374.

Tagnesi, K., Dumont, C., Rawlinson, C., \& Byrd, H. (2009). The CNO: Challenges and Opportunities on the Journey to Excellence. Nursing Administration Quarterly, 33(2), 159-167.

Tammaru, T., \& Kiitam, A. (2010). Excellence model and national quality promotion in 
Estonia. 7th International DAAAM Baltic Conference" INDUSTRIAL ENGINEERING.

Tutuncu, O., \& Kucukusta, D. (2010). Canonical correlation between job satisfaction and EFQM business excellence model. Quality \& Quantity, 44(6), 1227-1238.

Wasti, S. A. (2005). Commitment profiles: Combinations of organizational commitment forms and job outcomes. Journal of Vocational Behavior, 67(2), 290-308.

Weng, Q., McElroy, J. C., Morrow, P. C., \& Liu, R. (2010). The relationship between career growth and organizational commitment. Journal of Vocational Behavior, 77(3), 391-400.

Wong, C.-S., Wong, Y., Hui, C., \& Law, K. S. (2001). The significant role of Chinese employees' organizational commitment: implications for managing employees in Chinese societies. Journal of World Business, 36(3), 326-340.

Zangaro, G. A. (2001). Organizational commitment: A concept analysis. Nursing Forum; Philadelphia, 36(2), 14-21.

\section{Copyright Disclaimer}

Copyright for this article is retained by the author(s), with first publication rights granted to the journal.

This is an open-access article distributed under the terms and conditions of the Creative Commons Attribution license (http://creativecommons.org/licenses/by/4.0/). 